\title{
Life Skills in a Minute: Sending a Card ${ }^{1}$
}

\author{
Heather Janney ${ }^{2}$
}

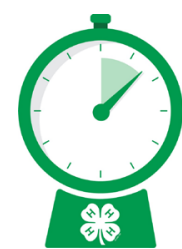

Have you ever received a greeting card in the mail? Receiving a card in the mail is an awesome experience: pulling it out of the mailbox, reading the outside of the envelope, breaking the seal, pulling out the card, reading the note from the sender, and then placing it somewhere special. A lot of families keep their special cards and a stash of greeting cards just in case they run into a time when they really need one and do not have time to run to the store. There is always a perfect card for an occasion, and sometimes a card requires no occasion at all other than thinking of someone. Below are some guidelines to help with sending greeting cards.

\section{Know the Person}

It is important to know the person to whom you are sending the card. You need to have an idea of their personality because you want your card to be received well and not perceived as inappropriate. You must consider if you might offend this person with the card you send. You don't want your positive intention to be misinterpreted or distorted. If you are ever unsure, go with a neutral card; avoid random humor or things that could be misunderstood. You want the recipient to get a smile from something they truly find funny, the heartfelt sincerity, or even the way you know what they would like to hear.

\section{Choose the Best}

If you are choosing a card at a store, look for the highest quality card and envelope. Your special attention to detail will be noticed by the recipient and will make the experience more memorable. However, the option of going to a store is not always available. If you have cards sitting around at home, you can go through them and find the best ones. Finally, do not send a crumpled card or envelope.

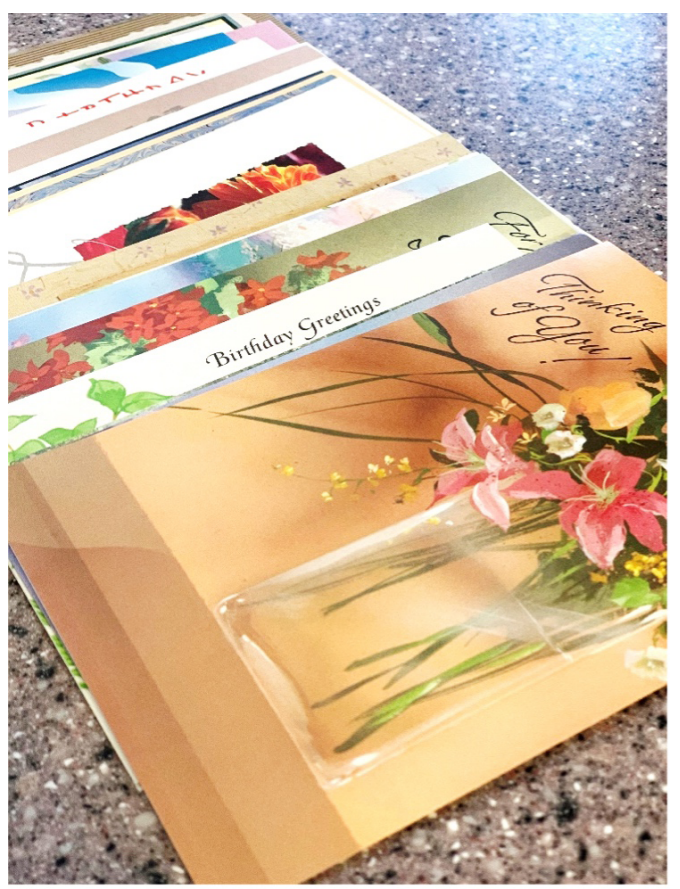

Figure 1. Many people keep a stack of blank multioccasion cards for those last-minute needs.

Credits: Heather Janney, UF/IFAS

\section{Handwritten}

Handwriting is the most important part of sending a card. This is what makes mailing a physical card to someone's home more special than any e-card, email, text, or digital message. The card you select will likely have something

1. This document is $4 \mathrm{H} 416$, one of a series of the 4-H Youth Development Department, UF/IFAS Extension. Original publication date August 2021. Visit the EDIS website at https://edis.ifas.ufl.edu for the currently supported version of this publication.

2. Heather M. Janney, county Extension director and Extension agent II, MS, UF/IFAS Extension Columbia County, Lake City, FL 32055.

The Institute of Food and Agricultural Sciences (IFAS) is an Equal Opportunity Institution authorized to provide research, educational information and other services

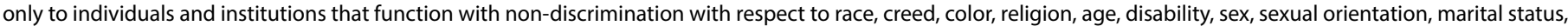

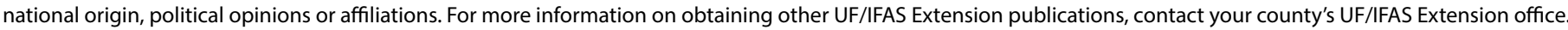
U.S. Department of Agriculture, UF/IFAS Extension Service, University of Florida, IFAS, Florida A \& M University Cooperative Extension Program, and Boards of County Commissioners Cooperating. Nick T. Place, dean for UF/IFAS Extension. 
printed on the interior, but that is not enough. Only adding your signature is not acceptable either. Compose a message to include inside. No essay is needed. Write something to let the recipient know you thought of them. Slang and bad grammar are not acceptable. Spend the time writing out a rough draft on a sheet of notebook paper first. Not everyone has the best handwriting or the best grammar. However, when you write it on a separate sheet of paper first, you can ask someone else to review for spelling and grammatical errors and take your time to write it in the card more carefully. Your personal message will be one of a kind and will add the touch needed to make the recipient smile. This will be the hug and the in-person greeting your recipient needs. Finally, check your pen for bleeding or running, and use clear colors of ink for readability.

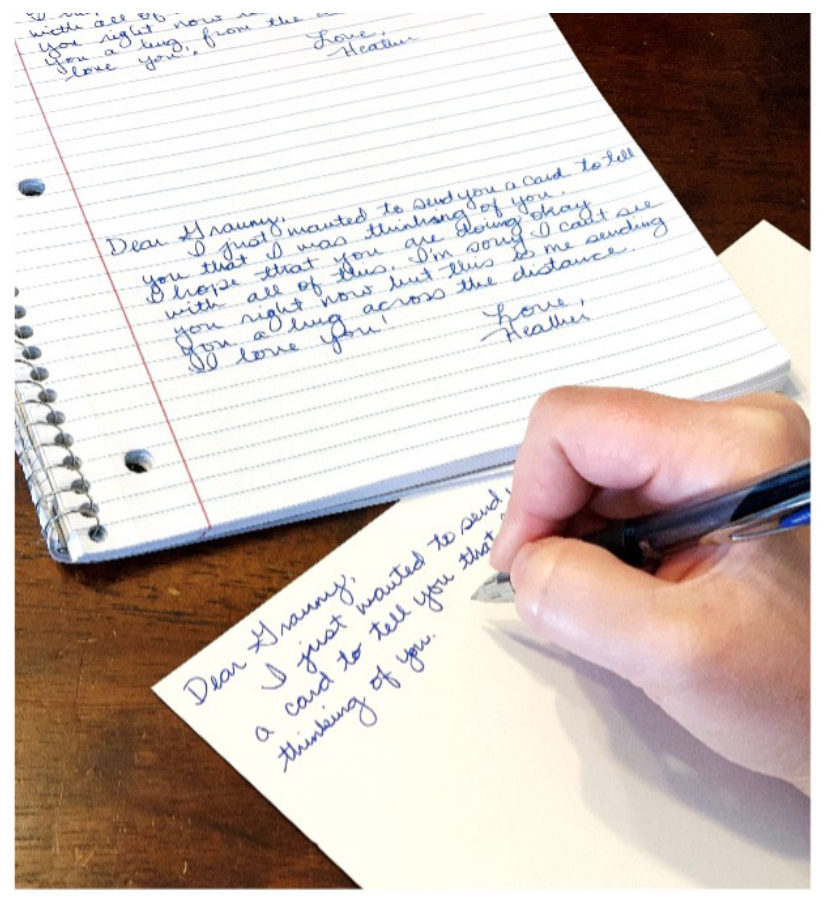

Figure 2. Handwrite a message inside of your card, but be sure to practice first.

Credits: Heather Janney, UF/IFAS

\section{Addressing the Envelope}

Just as handwriting inside the card is important, the address on the outside is too. Plus, addresses that are clearly written will help the US Postal Service deliver it to the correct place. Be sure to use blue or black ink that will be clearly legible. There is a correct format to writing the address on an envelope. Your return address (where you would accept mail) should be written on the upper left-hand corner of the envelope or on the back flap, depending on the size/ shape of the envelope. The recipient's address should be on the front and centered. It would start below your return address if the envelope design requires it to be on the front. The stamp would be placed in the top right-hand corner of the envelope. Don't forget the stamp. You can purchase stamps online, and your postal carrier will drop them in your mailbox. Depending on the size and weight of the card, there may be a different cost than that of a standard stamp. If you are unsure, always visit your local post office for the correct postage amount.

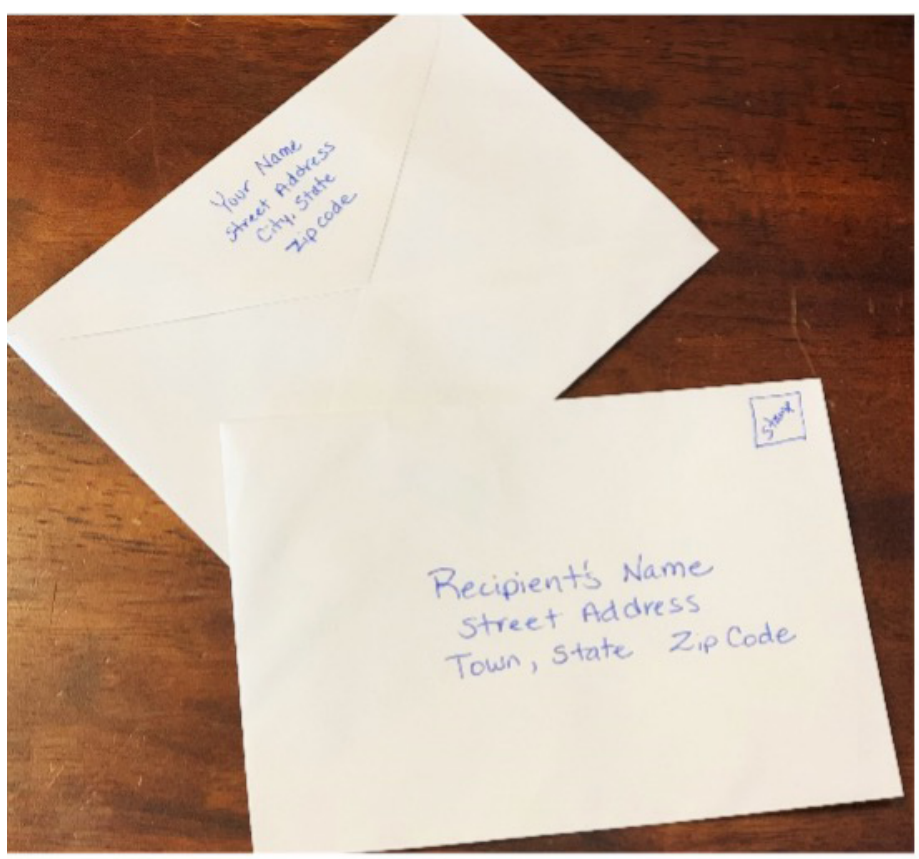

Figure 3. Addressing option for envelopes with extra space on the back flap.

Credits: Heather Janney, UF/IFAS

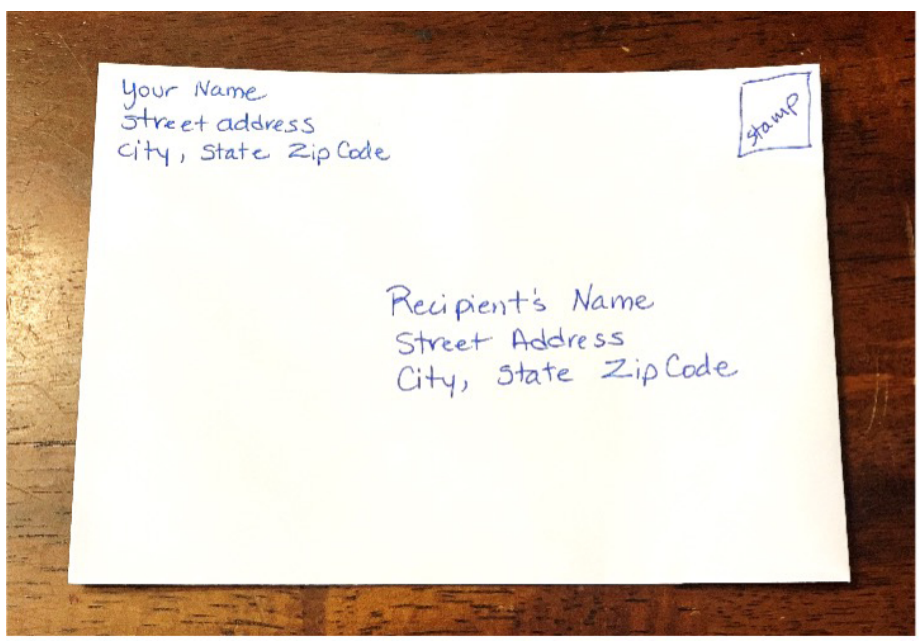

Figure 4. Return address and destination address on front of envelope. Credits: Heather Janney, UF/IFAS

\section{Mailing}

When including a check or cash in a card, ensure that it is not visible through the envelope when held up to light. Make sure any bulges are smoothed over if multiple bills or items are included, and properly seal the envelope so that nothing slips out. Once you have confirmed things are safely secured, place your card in one of the postal boxes at the post office or place it in your mailbox outside. Lift the 
flag so your postal carrier knows that there is something inside to pick up. Depending on your skills and the postal service, it should not take long to arrive.

\section{Source}

United States Postal Service. (2021). Sending mail. Available at https://www.usps.com/ship/letters.htm 